Revue de l'Institut des langues et cultures

d'Europe, Amérique, Afrique, Asie et Australie

27 | 2016

Approches ergonomiques des pratiques

professionnelles et des formations des traducteurs

\title{
Physical Ergonomics at Translators' Workplaces: Findings from Ergonomic Workplace Assessments and Interviews
}

Ergonomie physique du poste de travail du traducteur : résultats des évaluations et interviews

Ursula Meidert, Silke Neumann, Maureen Ehrensberger-Dow and Heidrun Becker

\section{OpenEdition}

Journals

Electronic version

URL: http://journals.openedition.org/ilcea/3996

DOI: $10.4000 /$ ilcea.3996

ISSN: 2101-0609

Publisher

UGA Éditions/Université Grenoble Alpes

Printed version

ISBN: 978-2-84310-336-0

ISSN: $1639-6073$

Electronic reference

Ursula Meidert, Silke Neumann, Maureen Ehrensberger-Dow and Heidrun Becker, « Physical Ergonomics at Translators' Workplaces: Findings from Ergonomic Workplace Assessments and Interviews », ILCEA [Online], 27 | 2016, Online since 08 November 2016, connection on 19 April 2019. URL : http://journals.openedition.org/ilcea/3996 ; DOI : 10.4000/ilcea.3996

This text was automatically generated on 19 April 2019

(C) ILCEA 


\section{Physical Ergonomics at Translators' Workplaces: Findings from Ergonomic Workplace Assessments and Interviews}

Ergonomie physique du poste de travail du traducteur : résultats des évaluations et interviews

Ursula Meidert, Silke Neumann, Maureen Ehrensberger-Dow and Heidrun Becker

The authors gratefully acknowledge the support of the Swiss National Science Foundation in carrying out this study. In addition, we would like to express our appreciation to the translators and their employers for letting us into their workplaces.

\section{Background}

1 Most Western professional translators are heavy computer users nowadays as the use of language technology and digital resources has become an essential aspect of their work. They spend long hours sitting at computer workstations, keying in text, scrolling through electronic documents, and searching for information on the web and databanks. They enter text and use input devices such as keyboards, touchpads or mice. These activities require constant repetition of the same specific movements and hence can cause an overload of muscles of the upper extremities and back. As a consequence, translators may be exposed to health issues known to be associated with computer work such as musculoskeletal ailments in the upper extremities, back, shoulders, arms and hands. There is also a serious potential for eyestrain with this type of concentrated work, especially if the size of the screen and/or font is too small.

2 According to Ming, Närhi and Siivola (2004), risk factors for this phenomenon are: (1) work-related factors (e.g., repetitive motions, forceful exertions or strain, awkward 
postures or unnatural positions and uncomfortable position of limbs); (2) personal characteristics (e.g., gender or body mass); and (3) environmental, sociocultural and psychological factors. The focus of the present study is on the work-related factors.

Pineau (2011) offers two explanations related to tool use for why these problems occur so frequently: the arrangement of letters and other keys on the standard keyboards used with most computers is not based on ergonomic considerations (the QWERTY layout was originally designed for mechanical typewriters to prevent the keys' metal arms jamming); and non-physiological movements are needed to type (such as hand distortions, overly frequent finger extension and imbalances between the use of the right hand and the use of the left hand).

Extended work on a computer also involves a static posture of the upper body. The neck supports the head, which is approximately one-seventh of the body weight. When a static posture has to be maintained over long hours, the muscles of the neck, shoulder and upper limbs frequently become overloaded and ultimately suffer injury (Ming et al., 2004). Other frequent problems are distortions in posture due to poor viewing angles of the screen and the position of the chair or desk. Such distortions may shorten the soft tissues, and cause muscle tension, weakness, fatigue and pain. Frequent computer work causes overload not only to the neck and shoulder area but also to the upper limb muscles and joints. When the tissues continue to be overloaded, ischemic cumulative injuries can occur, such as inflammation with swelling, nerve compression and deterioration of tendons and ligaments with provoked pain (Hagberg, 1996; Ming et al., 2004; Veiersted, Westgaard \& Andersen, 1990). Furthermore, eyestrain due to long hours spent looking at computer monitors can cause vision problems, known as Computer Vision Syndrome, with symptoms like headaches, ocular discomfort, dry eye, diplopia, and blurring either of near or distance vision (myopia and hyperopia, respectively). Rosenfield (2011) reports that $64-90 \%$ of computer users experience these symptoms, with a potentially negative effect on productivity. Ming, Närhi and Siivola (2004) report consequences such as pain, disability, impaired quality of work and life in general.

The physical work environment, such as the office layout, shared office space, the design of office furniture and the computer peripherals and their setting at the workplace, as well as situational aspects, such as ambient noise, lighting, room temperature and air humidity, may also represent risk factors for health and have an influence on the translators' work performance and well-being.

\section{The present study}

6 The study reported here is part of a larger research project, carried out from 2013-2015, which aimed to analyse and evaluate the cognitive and physical ergonomic factors that can impact the situated activity of professional translation. ${ }^{1}$ A recursive mixed-methods design was chosen for the project, which combined perspectives from translation studies, occupational therapy, usability testing and language technology. It included ethnographic observation of the translators' workplaces, ergonomic assessments of workplaces and tools, an online survey, interviews and focus groups, computer logging, screen recordings, video recordings, usability experiments, eye tracking, and retrospective verbalisations (the project is described in more detail in Ehrensberger-Dow \& Hunziker Heeb, 2016). In this article, the study related to the workplace and in particular the findings from the ergonomic assessments are reported and discussed. ${ }^{2}$ The 
goal of this study was to gain detailed information on ergonomic aspects of individual workplaces of professional translators and their effect on health, in order to make recommendations for ergonomic workplace settings. Characteristics such as the use and set-up of office chairs, computer screens or mice as well as environmental factors such as ambient noise, light, air quality and airflow are assumed to be related to health complaints such as stiff neck, back pain or dry eyes. Furthermore, we hypothesized that employment conditions (i.e., commercial staff, institutional staff and freelancers) would affect not only the workplace and its set-up but also the degree of control and selfregulation of the translation workflow and the translator's work itself.

\section{Method}

\section{Data collection and instruments}

7 The ergonomic assessments of the workplace involved inventories and observations of various aspects of the workplace set-up and its use while the translator was working (e.g., type of office chair and height in relation to the translator's height, leg length and desk height, number and type of screens and their set-up in relation to the translator working at the desk), as well as office characteristics such as office layout and size, lighting and glare, air quality, air flow and draft, ambient noise and other sources of disturbances. Observations and interviews took $2 \frac{1}{2}-3$ hours per workplace.

The assessment instrument was one that had been developed for internal use for ergonomic workplace assessments at the Zurich University of Applied Sciences (NeckHäberli \& Bregger, 2013). It consists of 15 items concerning the office layout, room climate and temperature, 21 items concerning lighting, glares and view, 11 items concerning the office desk, nine items concerning the office chair, and three items concerning footrests. Furthermore, there are 32 items related to the adjustment of the furniture and work equipment to the individual person working at that specific workplace (e.g., distance of face to the computer screen, height of the screen in relation to the eyes, etc.). These items followed general ergonomic recommendations closely (e.g., Ming et al., 2004; SUVA, 2014). Items were coded in binary categories (i.e., applies / does not apply).

Interviews included questions about disturbances and stressors from the workplace environment (e.g., noise, disturbances from colleagues, bad air quality, heat or cold), 48 items concerning health issues (recent health complaints, severity of complaint and impact of complaints on work), three questions on work arrangements (full or part-time employment, type of work) as well as 15 questions about breaks and other habits regarding work efficiency, ergonomics and compensatory activities (e.g., breaks, sports, hobbies).

Professional translators in various positions in Switzerland and Luxembourg were recruited by the research staff through personal networks, professional associations and employers. The participating translators were offered a free ergonomic consultation at their workplace as compensation for their participation. Each translator was visited by a team of two researchers (an occupational therapy researcher and a translation studies researcher) for several hours on a date and at a time convenient to the translator and the employer. The occupational therapy researcher performed the individual ergonomic assessment and observations, and the translation studies team member made video and 
screen recordings while the translator was working at the computer. The personal interview was carried out immediately afterwards with the translator. Data collection began in late 2013 and ended in the summer of 2014.

\section{Data analysis}

11 The collected data was entered into Excel spreadsheets and then imported into the statistics program SPSS 22. In the initial step, the data was descriptively analysed with respect to workplace ergonomics, health complaints, gender, age, position, office type and use of CAT tools. In the second step, relevant ergonomic items were identified according to the literature (e.g., SUVA, 2014) and were categorized with respect to the relevant body part (e.g., for the lower back the items "desk is adjustable in height", "backrest allows dynamic sitting position", "backrest supports lower back" among others were identified, for details see Appendix 1). On the basis of these items an ergonomic score of the workplace was made from the sum of these variables. Furthermore a cut-off was defined and binary variables were made in order to categorize workplaces as either ergonomically appropriate ("ergonomic workplace") or inappropriate ("less ergonomic workplace"). These binary variables were then related to reported health complaints, severity of complaints and impact on work. Chi-square tests were calculated to determine the significance of differences in responses.

\section{Results}

\section{Recruitment}

12 A total of 36 translators were recruited, 11 male (31\%) and 25 female (69\%). Nine participants (25\%) were working in the private sector as staff translators ("commercial"), 17 (47\%) were employed by institutions ("institutional"), and 10 (28\%) were working on their own account ("freelancers"). The age of participants lay between 25 and 62 with a mean of 45 years; one participant provided no information about the age. Translators were categorized as either high CAT tool users or low CAT tool users, based on their usual daily routine. The sample comprised 20 high CAT tool users (56\%) and 11 low CAT tool users (31\%). No information about CAT tool use was available from five (14\%) of the participants. The office space was categorized as an individual office, an office shared with one other person or an office shared with more than one other person. Out of the 36 participants, twenty-one translators (58\%) worked alone in an individual office, six (17\%) shared an office with one other person and seven (19\%) shared an office with more than one other person. Two people (6\%) could not be categorized (see Table 1). 
Table 1. - Overview of characteristics of recruited sample.

\begin{tabular}{|c|c|c|c|}
\hline & Characteristic & $\begin{array}{c}\text { No. of } \\
\text { participants }\end{array}$ & $\%$ \\
\hline \multirow[t]{3}{*}{ Sex } & Male & 11 & $31 \%$ \\
\hline & Female & 25 & $69 \%$ \\
\hline & Total & 36 & $100 \%$ \\
\hline \multirow[t]{4}{*}{ Age } & $<45$ & 16 & $44 \%$ \\
\hline & $45+$ & 19 & $53 \%$ \\
\hline & Not applicable & 1 & $3 \%$ \\
\hline & Total & 36 & $100 \%$ \\
\hline \multirow{4}{*}{$\begin{array}{c}\text { Employment } \\
\text { type }\end{array}$} & Commercial staff & 9 & $25 \%$ \\
\hline & Institutional staff & 17 & 47 \\
\hline & Freelancer & 10 & $28 \%$ \\
\hline & Total & 36 & $100 \%$ \\
\hline \multirow[t]{4}{*}{ Cat tool use } & High & 20 & $55 \%$ \\
\hline & Low & 11 & $31 \%$ \\
\hline & Not applicable & 5 & $14 \%$ \\
\hline & Total & 36 & $100 \%$ \\
\hline \multirow[t]{5}{*}{ Office type } & Individual office & 21 & $58 \%$ \\
\hline & $\begin{array}{l}\text { Shared office with one } \\
\text { person }\end{array}$ & 6 & $17 \%$ \\
\hline & $\begin{array}{l}\text { Shared office with } \\
\text { several people }\end{array}$ & 7 & $19 \%$ \\
\hline & Not applicable & 2 & $6 \%$ \\
\hline & Total & 36 & $100 \%$ \\
\hline
\end{tabular}

\section{Ergonomic assessments}

The following workplace-related items were measured: room layout, availability of meeting rooms and room for a break, room temperature and climate, lighting, office furniture, computer and other office tools and their set-up as well as organisation or workflow and the number, length, and frequency of breaks. The items for the ergonomic assessment are explained in detail below.

In regard to the room layout, all translators but two had enough space to pass through the office easily to their desk (95\%), and all (emergency) exits were accessible for all of them. Almost all (97\%) had access to a meeting room and a room for coffee breaks. In seven of the observed offices (19\%), obstacles on the ground (e.g., cables) which could cause stumbling or falling were found. Regarding noise insulation, nine (25\%) workplaces were inadequate, with ambient noise measured above 65 decibels. Room climate was also sub-optimal in many offices: 28 of 36 (i.e., $78 \%$ ) had temperatures above the recommended $23 \mathrm{C}^{\circ}$, and some were even above $27 \mathrm{C}^{\circ}$. The relative humidity levels were mostly adequate: only in three cases (8\%) were they under the recommended $30-65 \%$. All workplaces were draft-free.

The office desks in most cases were considered ergonomically appropriate. Nevertheless, there were a number of issues. Of the 36 workplaces observed, four desks had square edges that could cause injury (11\%), three ( $8 \%$ ) had a shiny surface that could cause glare, two (6\%) were made out of a material that is cold to the touch, two (6\%) were unstable and so wobbled slightly while the translator was typing or writing, and one (3\%) was considered too small. Even more problematic was the height of the working surface: for 
19 translators (53\%) the desks were not set at the right height; for 16 (44\%) the desks were not adjustable in height; and 13 translators (36\%) had no opportunity to work in a standing positon.

16 Concerning the seating arrangements, observations showed that four translators (11\%) did not have an office chair (i.e., their chairs were not adjustable in height, had no wheels and were not rotatable). Eleven of the others (31\%) had no possibility to adjust the backrest of their chairs, and the lumbar support of the backrest was not set at the right height on 16 of the chairs (44\%). The same percentage of backrests (44\%) was fixed, so did not allow for dynamic sitting. Six chairs (17\%) had no armrests, and of those that did, 12 (33\%) were not set at a height that allowed the translators to rest their elbows lightly on them. The chairs of 19 translators (53\%) were not adjusted to their height to allow the thigh to be in a horizontal or slight frontally sloping position. Furthermore, 22 translators (61\%) did not know how to adjust their chair to their needs.

17 A total of 14 translators (39\%) could not work with both feet touching the ground. Although footrests were available at 24 workplaces (67\%), for nine of those (25\%) the inclination could not be adjusted and 7 (19\%) were not made of anti-slip material. There was insufficient legroom under the desks at six of the workplaces (17\%).

18 At all but one workplace, the lighting was flicker-free (97\%). However, the light caused glare (14\%) at five workspaces and on six computer screens (17\%), and at five workplaces (14\%) a shadow fell onto the desktop because the light was set at an angle other than from the recommended right side and above. In 19 out of 36 workplaces (53\%), the light could not be dimmed, and at ten workplaces (28\%) no table lamp was available. At eight workplaces (22\%), there were no blinds on the windows.

19 In most cases the computer screens were set too high: the edge of 28 screens (78\%) was higher than the recommended 5 to $10 \mathrm{~cm}$ below the eye level of the translators. Eleven screens (31\%) were at the wrong distance from the translator because they were not within the recommended $60-80 \mathrm{~cm}$ from the face. Six screens (17\%) needed adjustment by tilting the lower edge slightly towards the face. Five screens (14\%) needed to be moved in order to be directly in front of the translator. Seven translators (19\%) did not have an external screen but had to use the one on the laptop, meaning that either the screen or the keyboard was at the wrong height.

Only one keyboard (3\%) lay directly in front of the translator. Most of them (61\%) were too far away from the body and were not set up to lie $10-15 \mathrm{~cm}$ from the edge of the desk. Half of the translators did not have the documents they were using positioned between the keyboard and the computer screen while working but instead had them at the side or between themselves and the keyboard.

Regarding workflow organisation, only 16 translators (44\%) had a good mix of tasks while $20(56 \%)$ had monotonous work. Many of them (44\%) were unaware about possibilities of integrating exercises and activities into their daily work. About one-third of the translators (36\%) did not change their sitting position enough to relieve the spine. This lack of movement was accentuated for the eight translators (22\%) who did not take any breaks. Of the rest, only $17(47 \%)$ took breaks for small exercises although 15 translators (42\%) had relaxation techniques integrated into their daily work. Three translators (8\%) did not regularly drink water while working, and $11(31 \%)$ paid insufficient attention to keeping their blood glucose level even. 


\section{Health complaints}

As shown in Figure 1, the most frequent health complaints that were reported concerned the eyes (mean of 2.6 on a 6-point scale from "practically never" = 1 to "always" =6) with only $25 \%$ of participants reporting almost never having eyestrain or other eye disorders. ${ }^{3}$ The next most common complaints involved the shoulder area (mean of 2.6; with only $28 \%$ having complaints practically never) and neck (mean of 2.4 ; with $28 \%$ having complaints practically never).

Figure 1. - Frequency of recent complaints in percent.

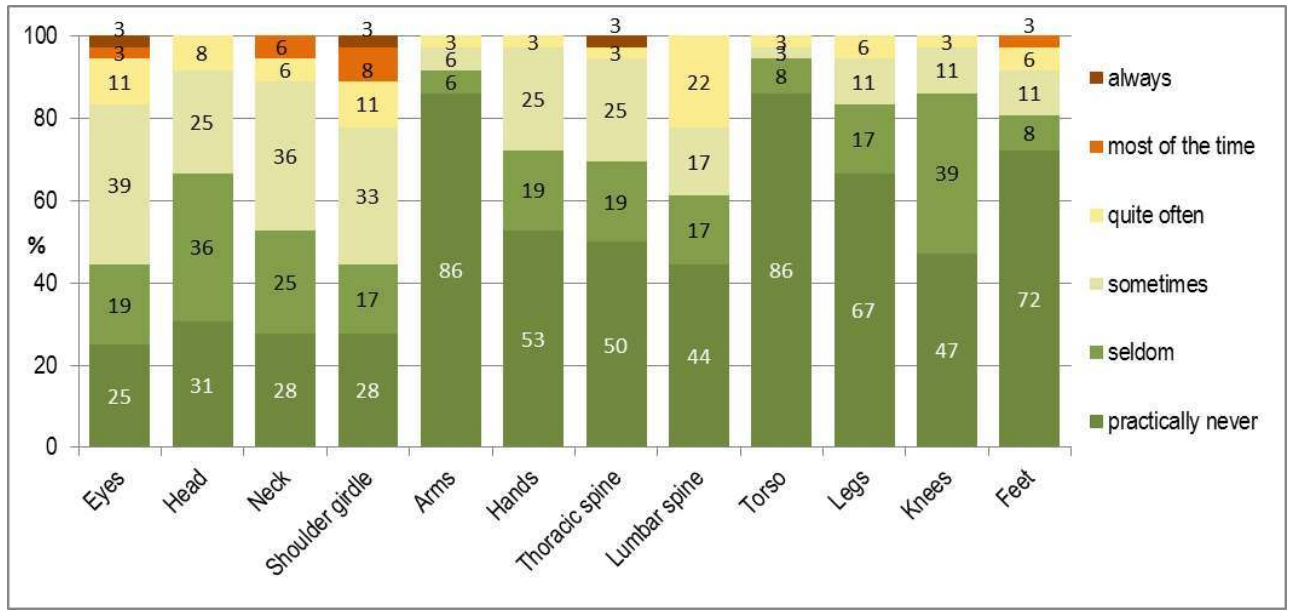

Practically no health complaints were reported in the torso (mean of 1.2; 86\%), arms (mean of $1.3 ; 86 \%$ ) and feet (mean of $1.6 ; 72 \%$ ). Overall, the frequency of complaints was quite low (mean of 1.9). The severity of complaints reached a mean of 2.1 overall in a range from 1 "not at all", 2 "very minor", 3 "minor", 4 "somewhat", 5 "severe" to 6 "very severe".

Translators were asked to what extent the reported ailments interfered with work. The overall mean for the items was 1.8 in a range of 1 "not at all", 2 "very little", 3 "slightly", 4 "somewhat", 5 "definitely" to 6 "very much so". ${ }^{4}$ Most interferences with work because of complaints were reported concerning the head (mean of 2.4), eyes (mean of 2.3), neck (mean of 2.2) and shoulder girdle and hands (both means of 2.1). Very little interference were reported due to complaints in the torso (mean of 1.1), legs (mean of 1.2), knees and arms (both means of 1.3) as well as feet (mean of 1.4).

In general, women reported more complaints than men did (overall means of 2.0 and 1.7, respectively). The only exceptions were slightly more frequent ailments reported by men in the arms and torso (see Figure 2). The severity of complaints was also higher among women (mean: 2.3) than men (mean: 2.0), although the interference with work caused by ailments was nearly the same (mean for women: 1.8; mean for men: 1.7). 
Figure 2. - Frequency of recent ailments by gender.

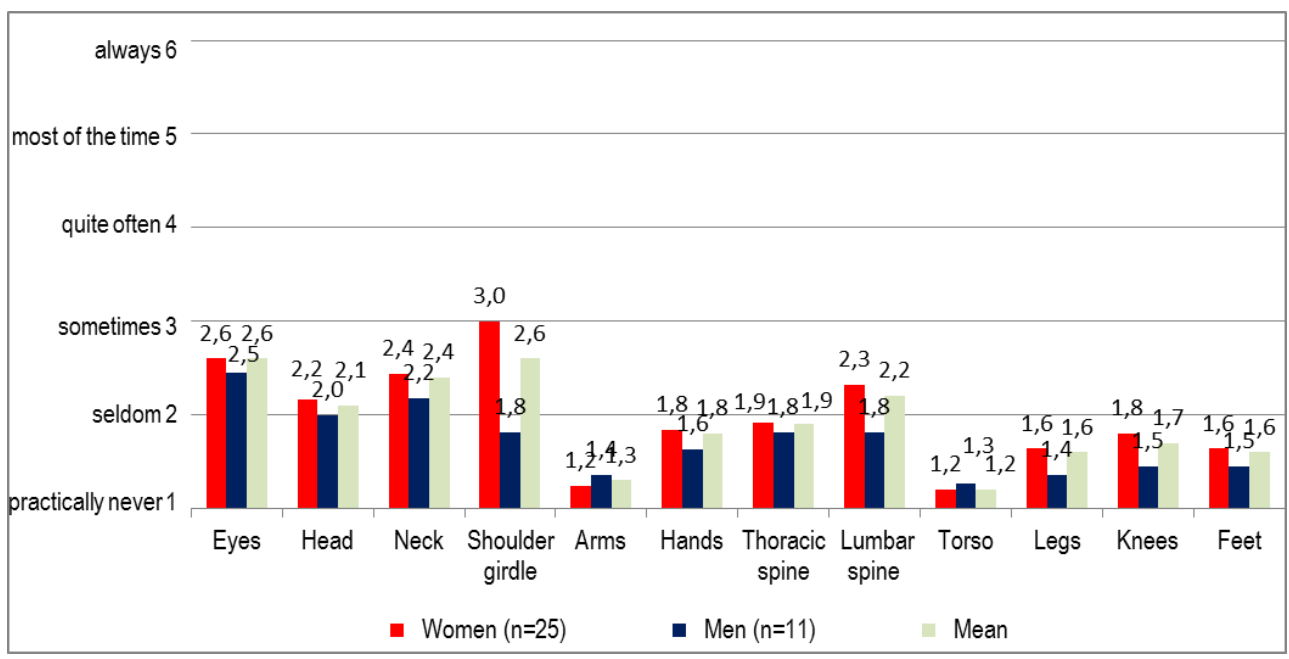

In regard to age, the literature suggests that there is a correlation between age and reported ailments (Evans \& Patterson, 2000). Due to the general ageing process, ailments are more often reported among older people (Ming et al., 2004). To test whether this can be observed in our sample, we grouped participants into three approximately even age categories (i.e., 35 and younger; 36-50, and 51 and over; see Figure 3). ${ }^{5}$ The comparison among the three age categories showed no differences, as the overall mean for the items in all three age groups was 1.9. The hypothesis that older professionals reported complaints more often than younger translators was not supported: in fact, younger professionals more often report complaints in eyes, shoulder girdle and thoracic spine than the older groups do (see Figure 3).

Figure 3. - Frequency of recent ailments by age category.

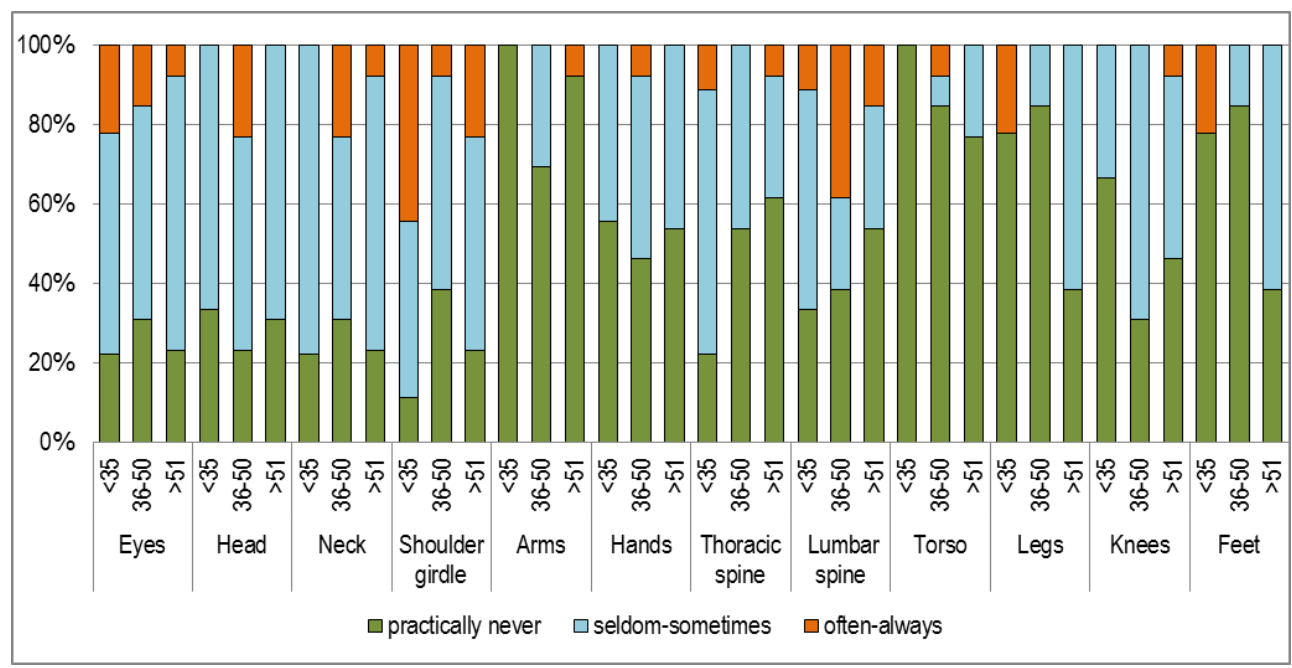

With respect to employment position, ailments were more frequently reported by commercial employees (mean of 2.0) than by freelancers (mean of 1.9) and translators working in an institutional setting (mean of 1.8; see Figure 4 for a breakdown by complaint). However, the severity of complaints was highest among freelancers (mean of 2.4), followed by commercial staff (mean of 2.2) and institutional staff (mean of 2.1). 
Impact on work was the same for freelancers and commercial staff, with a mean of 1.8, and less for institutional staff (mean of 1.7).

Figure 4. - Frequency of recent ailments by position.

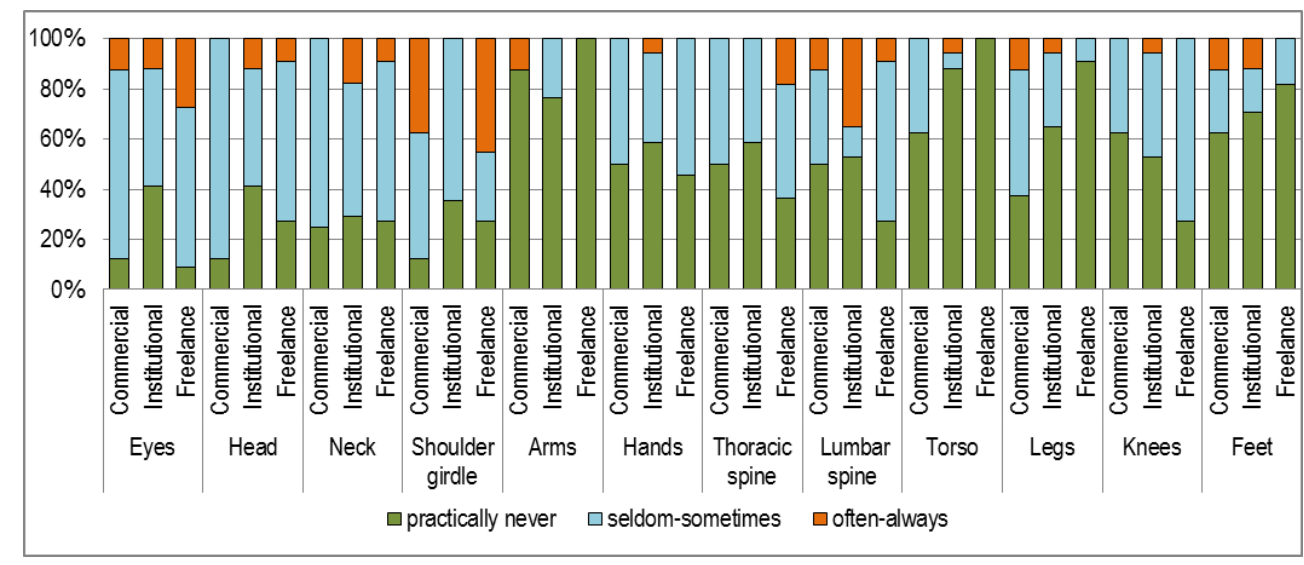

The analysis of frequency of ailments showed only slight differences depending on CAT tool use (Figure 5). Low users of CAT tools had slightly more frequent health complaints (mean of 2.0) than high users did (mean of 1.9). In addition, complaints were more severe (mean of 2.4) for low users of CAT tools than for high users (mean of 2.1). The ailments interfered with work to the same degree for both groups (mean of 1.7).

Figure 5. - Frequency of recent ailments by level of CAT tool use.

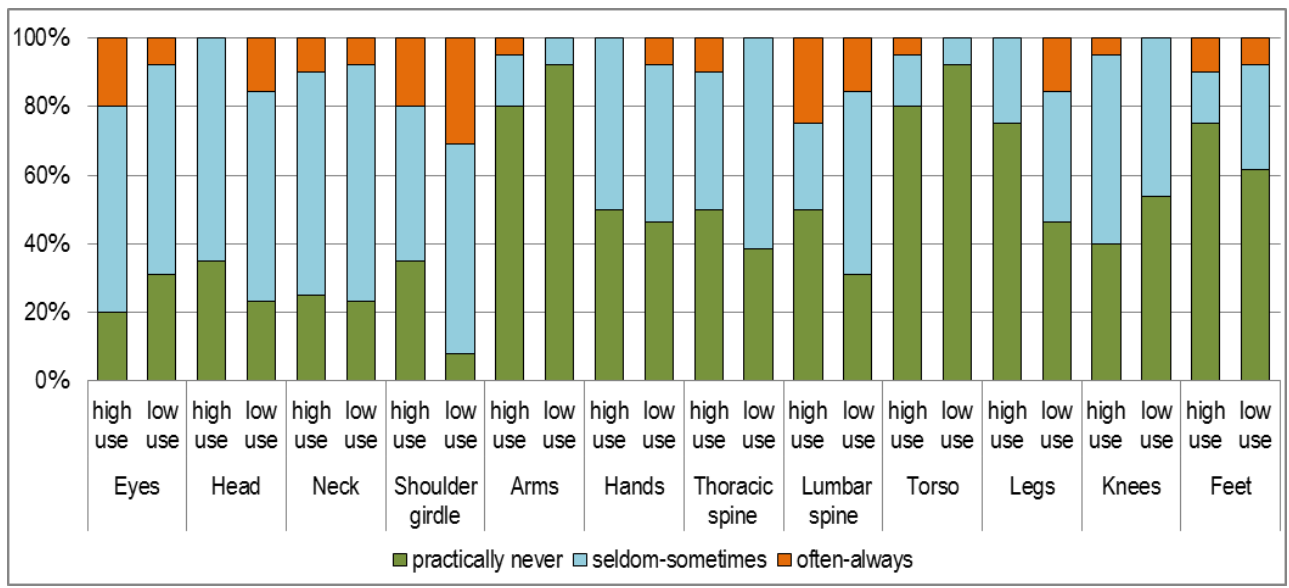

With respect to office layout, translators working alone reported less frequency of complaints (mean of 1.8) than translators working in an office shared with another person (mean 2.1) or shared with several people (mean of 2.1). The severity of ailment was also higher among translators in shared offices (mean of 2.0 vs. 2.3 and 2.2 respectively). Impact on work, however, was least in an office shared with one other person (mean 1.6) followed by offices shared with several people (mean 1.7), and highest for those working alone (mean 1.9).

Taking into account the amount of time spent working, the analysis showed that translators working part-time (i.e. less than $70 \%$ ) reported more frequent ailments (mean of 2.1) compared to translators working full-time (mean of 1.8). 
31 The comparison between ergonomic workplaces to those with a more unfavourable workplace in regard to ergonomics showed that translators of both groups often had about the same frequency of ailments. However, the severity and impact of the ailments on work were higher for translators working in low-ergonomic workplaces, especially in the neck, shoulder girdle, thoracic spine, torso, knees and legs. Due to the small sample size and low variance in the sample, though, most items were below significance as tested with the chi-square distribution (see Table 2). No clear relation of workplace ergonomics and ailments could be found for the head, lumbar spine, eyes, feet and hands.

Table 2. - Relation of workplace ergonomics to reported ailments, ailment severity and impact on work.

\begin{tabular}{lccccccccccc}
\hline & Eyes & Head & Neck & $\begin{array}{l}\text { Shoulder } \\
\text { girdle }\end{array}$ & Arms & Hands & $\begin{array}{l}\text { Thoracic } \\
\text { spine }\end{array}$ & $\begin{array}{l}\text { Lumbar } \\
\text { spine }\end{array}$ & Torso & Legs & Knees \\
\hline $\begin{array}{l}\text { Reported } \\
\text { ailments }\end{array}$ & no & no & yes & yes* & yes & no & yes & no & yes & yes & yes* \\
$\begin{array}{l}\text { severity of } \\
\text { ailments }\end{array}$ & no & no & yes & yes & yes & no & yes & no & yes & yes & yes* \\
$\begin{array}{l}\text { impact of } \\
\text { ailment on } \\
\text { work }\end{array}$ & no & no & yes* & yes* & no & no & yes* & no & yes & yes & yes* \\
\hline
\end{tabular}

Image 200000090000A788000022D4CB00F6C2.wmf

* SIgNIfICANT P<0.05 OR LOWER WITH THE CHI-SQUARE TEST

32 Figure 6 shows the relative distribution of the frequency of recent shoulder girdle and knee ailments depending on whether the workplace was considered ergonomic or evinced low ergonomics. These ailments are reported significantly less frequently by those who work in ergonomic workplaces.

Figure 6. - Frequency of recent ailments in shoulder girdle (left; $p<0.05)$ and knees (right; $\mathrm{p}<0.0001$ ).

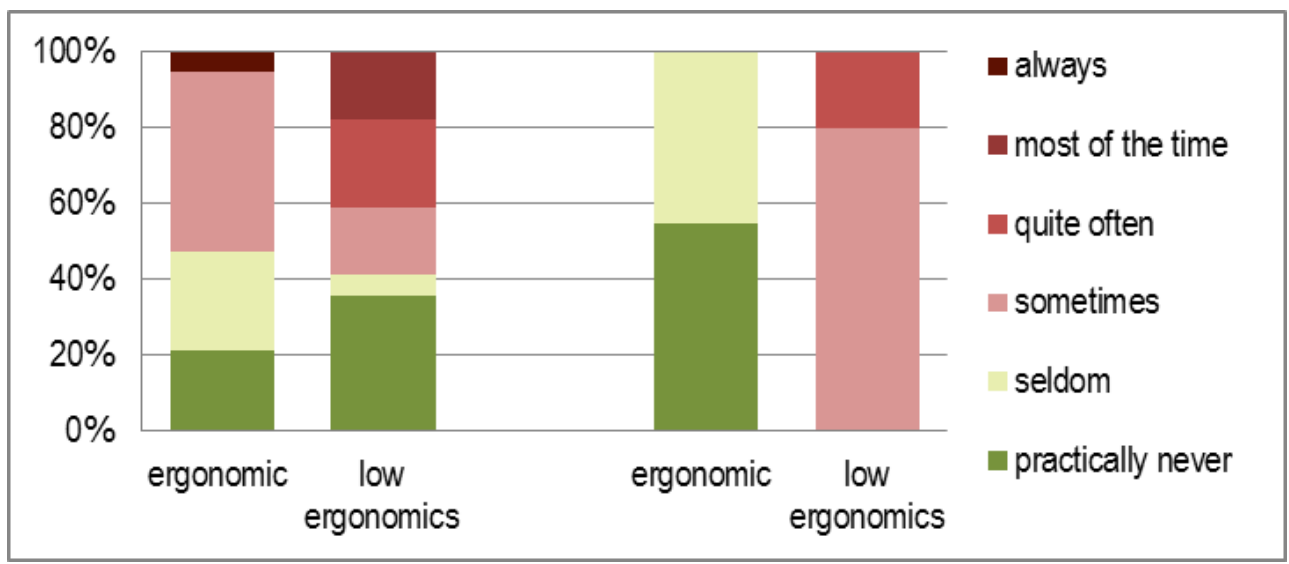

33 A similar pattern emerges with respect to the severity of ailments in the shoulder girdle and knees (see Figure 7), with low ergonomics more closely linked to more severe ailments and the translators working at ergonomic workplaces reporting less severe ailments. Corresponding to this, these ailments had a significantly lower impact on the translators working in ergonomic settings (see Figure 8). 
Figure 7. - Severity of recent ailments in shoulder girdle (left; $n . s$.$) and knees (right; p<0.01$ ).

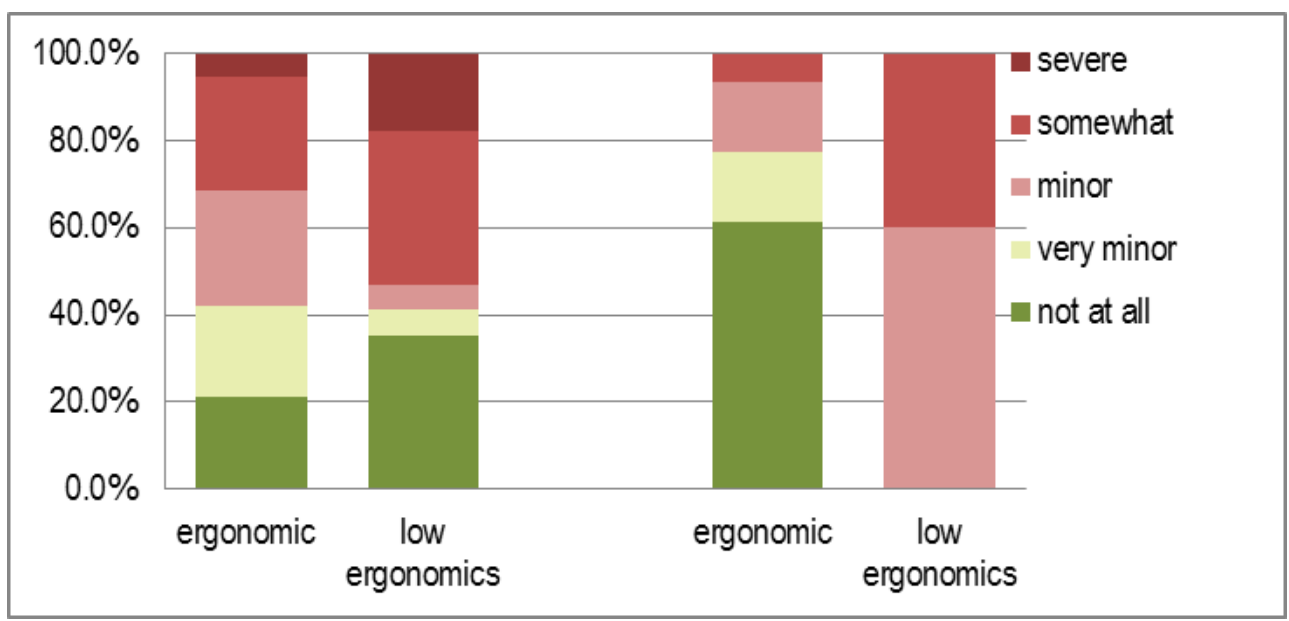

Figure 8. - Impact of recent ailments in shoulder girdle (left; $p<0.05)$ and knees (right; $p<0.001$ ).

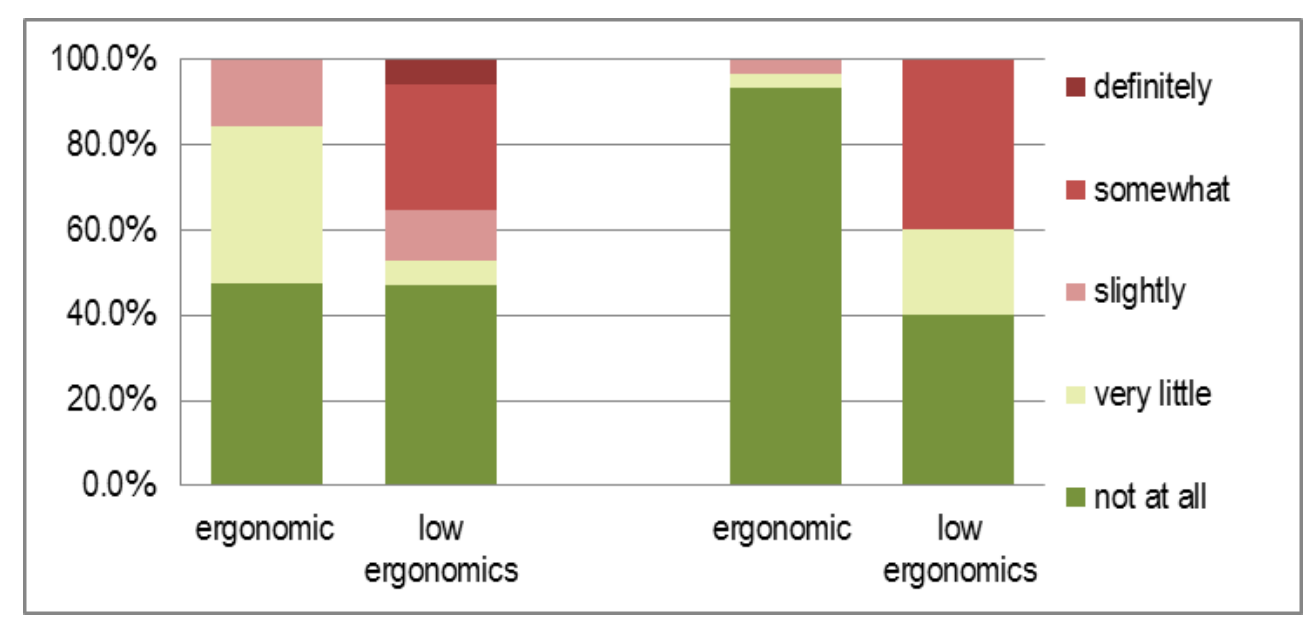

\section{Discussion and Recommendations}

The analysis of our data showed generally low levels of health complaints and a high ergonomic standard of equipment and furniture at translators' workplaces. The ailments that were most frequently reported were in the shoulder girdle, eyes, neck and head, which is typical of frequent computer use. Female translators reported more complaints and with greater severity than men did. No clear age-related effects were found. On the contrary, younger professionals actually reported complaints related to the eyes, shoulder girdle and thoracic spine more frequently than the older groups did. This suggests that the older groups are taking measures to reduce stress in this area, perhaps as a result of previous problems. No exposure effect was found, either, since part-time workers tended to have more complaints than full-time employees. It would be interesting to do a further study in this area, to determine whether their part-time status was completely by choice or prompted by health issues. Commercial staff report the most frequent occurrence of ailments followed by freelancers and institutional staff. Freelancers, however, report the highest severity of ailments. Translators working in offices by themselves reported fewer and less severe problems than those sharing an 
office space with others. Translators who were high users of CAT tools had slightly fewer complaints with less severity than those with low use of CAT tools. This could be related to the easing of load on working memory and the elimination of tedious, repetitious tasks that the use of these tools entails, which allows translators to focus on more interesting problems and reduces the necessity to input text manually (O'Brien, 2012).

The workplaces in the companies and institutions that were assessed in this study had a high ergonomic standard. However, complaints did occur most often in the areas of the body that are frequently overstrained by intensive computer use and sitting upright in a static position. Body parts most often involved were in the upper body, including the shoulder girdle, neck, head and eyes.

The physical ergonomics at the freelancers' workplaces were often sub-optimal since most of them worked at home, and while some did have dedicated workplaces in their homes, others did not. In the latter case, translators' workplaces were set up at kitchen tables or other makeshift workplaces, and they worked on laptops with only small screens, sitting on ordinary chairs, etc. Such workplaces were not set up ergonomically enough to allow the body to rest in a comfortable and natural position. It is therefore not surprising that the freelancers in this study reported the most severe impact of ailments. Freelancers' workplaces therefore have the most potential for improvement and thus prevention of ailments caused by frequent computer use and static posture. Stable work arrangements in which the ergonomics are permanently implemented are therefore highly recommended.

The possession of ergonomic office furniture and tools does not necessarily imply appropriate use of them. Although ergonomic furniture and equipment were in place at many of the dedicated workplaces, they were often not adjusted correctly for the translator using them. Individualized adjustments of furniture and tools to the body and personal needs of the translator are therefore strongly recommended. Frequent switching or sharing of workplaces often hinders an ideal ergonomic set-up because translators might not take the time necessary to adjust the workplace furniture to their posture and personal needs. This could be a reason for our finding that part-time translators had more health complaints than full-time translators did, which contradicts other findings reported in the literature (Evans \& Patterson, 2000) showing that the number of hours spent on the computer is a predictive factor for tension and ailments in the neck and shoulder area. Other possible explanations for this finding are that translators with health complaints reduce their workload and that part-time translators are more under more pressure to complete their tasks in fewer working hours. As expected from the literature (Case \& Paxson, 2005; Evans \& Patterson, 2000), female translators reported more health complaints than male translators did. While some authors suggest that this is due to socialisation and cultural differences between the sexes in the reporting of symptoms and a greater willingness for women to talk about symptoms (Case \& Paxson, 2005), others suspect that the cause lies in the additional work done at home as a homekeeper (Evans \& Patterson, 2000).

There was little variance concerning health complaints in this study. Most participating translators reported relatively few complaints and considered them as not particularly severe. Furthermore, they reported that the complaints had relatively little impact on their work. However, interviews revealed that many translators had had health complaints in the past that were considered severe and disruptive to the workflow (e.g., 
back pain). In addition, translators reported that after the complaints became severe they changed certain aspects of their workplaces (e.g., they bought a new office chair or started using a foot rest). After these changes, the health complaints decreased or ceased. This "learning from negative experience" could be a reason for the absence of an ageeffect in our study, in contrast to what has been documented in similar studies (Evans \& Patterson, 2000). Such learning from negative experience, however, is unnecessary and painful, since ergonomic furniture and tools are readily available on the market at moderate prices. Furthermore, information on ergonomic posture and workplace set-up is freely available on the internet from reliable sources. ${ }^{6}$

Based on the findings in this study, we can make the following recommendations for professional translators:

- If possible, ask for an individual workplace consultation from someone trained in physical ergonomics in order to make optimal use of the office furniture and tools that are already available and to receive individualized advice about possible new purchases.

- Have a designated workplace that is set up in a way that minimizes overuse of tendons and muscles in the hands, arms, shoulder and upper back and that gives the body optimal support.

- Take breaks frequently and change position at regular intervals (e.g., by standing up to do revision work or by doing exercises to help relax the muscles that otherwise become strained through maintaining a static posture).

- Engage in compensatory activities when not at work, such as sports, muscle relaxation exercises and spending time outdoors.

41 Since problems were more frequently observed among freelancers and were also noticeable among younger professionals as well, to prevent learning by negative experience, we recommend that:

- Basic ergonomic knowledge be integrated into professional training.

- Basic ergonomic training be provided in further education courses.

- Information about ergonomics be disseminated through professional associations and similar channels.

\section{Further directions}

The recruitment of translators willing to participate in workplace observations was difficult: it seemed that certain employers were not willing to let their employees take part in the study. Although the original design had foreseen observations at 48 workplaces, it was only possible to complete 36 by the end of the study. Companies and freelancers were the most likely candidates to decline participation, presumably because workplace observations and interviews would take time away from work. We assume that, in addition to this resource problem, the interest in making screen and video recordings of the processes was the main reason why several companies refused their employees permission to participate, despite the translators wanting to do so. This resulted in an over-proportion of institutional employees (17 out of a total of 36) in our data and an underrepresentation of commercial employees and freelancers (nine and 10, respectively). The study results therefore contain a bias and make no claims to being representative of the translation market in Switzerland. Furthermore, the small number of participants in the study precluded the use of more sophisticated statistics such as regression analysis to isolate effects. For further investigation about workplace 
ergonomics on health in translators a greater number of observations could give more insight on the significance of ergonomic items on health and be able to tell effects apart. This might be achieved with additional incentives for participation (although the translators in this study received a free ergonomic assessment including a written report with recommendations).

Another problem that we faced was that translators often had more than one position (e.g., freelancer and part-time staff translator at a company or institution) and therefore more than one workplace. For the purposes of this study, we made observations and recordings at only one of the workplaces and categorized the person according to where those were made. Results concerning position therefore have to be interpreted with caution.

The translators who took part in the study generally had few health complaints and were reasonably well-equipped with respect to ergonomic furniture at their workplaces. It is possible that only translators, institutions and companies that were already sensitized to ergonomics and work-related health issues were interested in participating in the study. That sensitivity may have resulted in better workplace arrangements than those of translators and employers that are unaware of the importance of these issues. Alternatively, translators with poorly-equipped workplaces may have been hesitant to participate in the study out of fear of embarrassment. Another important consideration is that Switzerland and Luxembourg are both high-income countries in which workplaces are usually modern and well-equipped. Almost half the observed workplaces (47\%) were in an institutional setting such as the European Parliament or the Swiss federal government, both of which are institutions with a high standard of workplace ergonomics. A greater variety of workplace observations in other regions of Europe and with translators in commercial and freelance settings would provide a more balanced picture. ${ }^{7}$ In addition, a greater number of observations would allow the use of statistics to hold factors of workplace, individual factors and ambient factors apart and reveal which factors have more impact on health and which are more negligible.

Reported health issues in this study can be tentatively associated with workplace ergonomics. However, a longitudinal or follow-up design would allow stronger claims of cause and effect to be made. Other research designs within the framework of action research might also allow an analysis of the impact of ergonomic workplace interventions on health outcomes in the interest of improving the working conditions of translators worldwide.

\section{BIBLIOGRAPHY}

CASE Anne \& PAXSON Christina (2005), "Sex differences in morbidity and mortality", Demography, 42(2), 189-214. 
EHRENSBERGER-Dow Maureen \& HUNZIKER HEEB Andrea (2016), "Investigating the ergonomics of a technologized translation workplace”, R. Muñoz Martín (dir.), Reembedding Translation Process Research, Amsterdam/Philadelphia: John Benjamins Publishing Company, 69-88.

EVANS Owen \& PATTERSON Kim (2000), "Predictors of neck and shoulder pain in non-secretarial computer users", International Journal of Industrial Ergonomics, 26(3), 357-365.

HAGBERG Mats (1996), “ABC of work related disorders. Neck and arm disorders”, BMJ: British Medical Journal, 313(7054), 419.

Ming Zhiyong, NÄRHI Matti \& SIIVola Jouko (2004), “Neck and shoulder pain related to computer use", Pathophysiology, 11(1), 51-56.

NECK-HÄBERLI Regula \& BREGGER Vera (2013), Erhebungsinstrument zur ergonomischen Arbeitsplatzberatung, Fachstelle Betriebliches Gesundheitsmanagement, Winterthur: ZHAW (unpublished document).

O'BRIEN Sharon (2012), “Translation as human-computer interaction”, Translation Spaces, 1, 101-122.

PINEAU Martine (2011), “La main et le clavier : histoire d'un malentendu”, ILCEA (14), < ilcea.revues.org/index1067.html>.

ROSENFIELD Mark (2011), “Computer vision syndrome: a review of ocular causes and potential treatments", Ophthalmic and Physiological Optics, 31(5), 502-515.

SUVA (2014), Bildschirmarbeitsplatz. Wichtige Informationen für Ihr Wohlbefinden, Luzern: SUVA.

Veiersted Kaj Bo, WestgaARd Rolf \& Andersen Per (1990), "Pattern of muscle activity during stereotyped work and its relation to muscle pain", International Archives of Occupational and Environmental Health, 62(1), 31-41.

\section{APPENDIXES}

Appendix 1. - Items in the ergonomic assessment and relation to body part. 


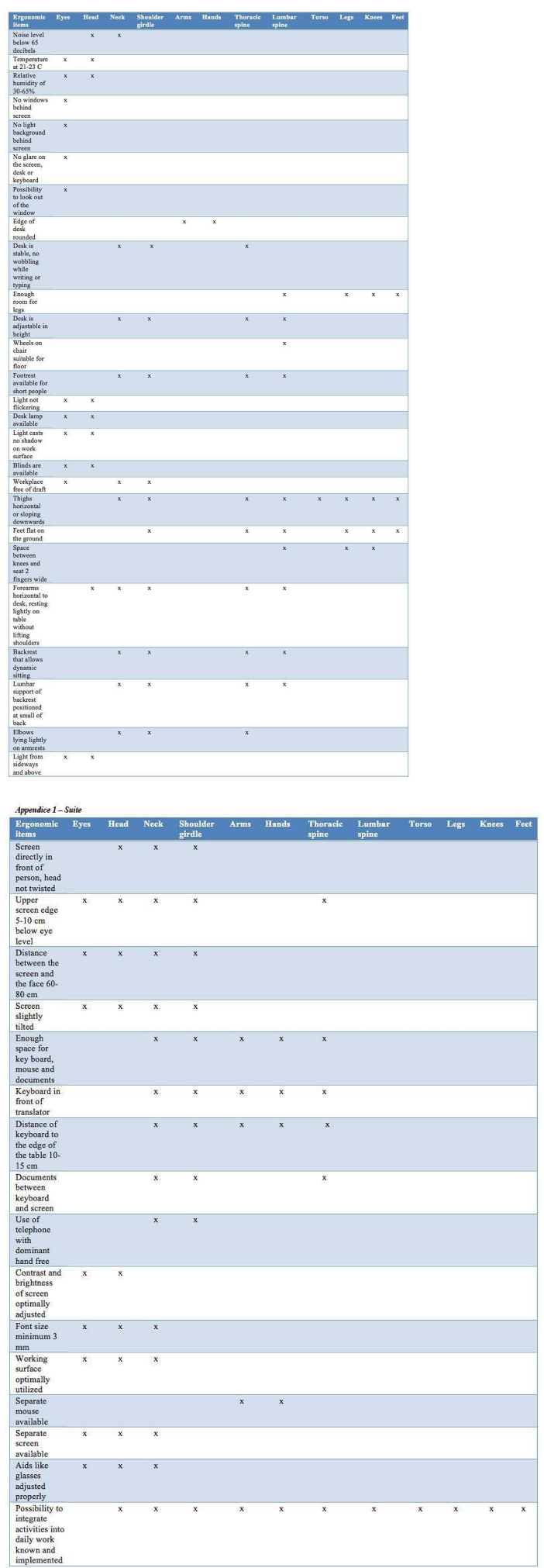

\section{NOTES}

1. For more information on the larger research project, see <www.zhaw.ch/linguistics/ergotrans $>$. 
2. Findings from the online survey are reported in Ehrensberger-Dow et al., in this special issue.

3. The scale was presented in German: 1 = so gut wie nie; 2 = selten; $3=$ manchmal; $4=$ ziemlich oft; 5 = meistens; 6 = immer.

4. The scale was presented in German: $1=$ keine, $2=$ sehr leicht, $3=$ leicht, $4=$ mässig, $5=$ stark, $6=$ sehr stark. The English translations used in this article are $1=$ not at all, $2=$ very little, 3 = slightly, 4 = somewhat, 5 = definitely, 6 = very much so.

5. Due to limited amount of data and for the purposes of simplification, we have thus collapsed the health categories into the three categories of "practically never", "seldom to sometimes" and "often to always" for the results summarized in Figure 3 and the following figures.

6. For example, in German, French, Italian and English from the Swiss SUVA Accident Insurance Fund (<www.suva.ch/startseite-suva/service-suva/lernprogramme-suva/bildschirmarbeitsplatzeinrichten-suva.htm>).

7. The international survey done in the final phase of the Physical and Cognitive Ergonomics of Translation project is a step in this direction.

\section{ABSTRACTS}

Most professional translators in the Western world are heavy computer users and thus may be exposed to health risks known to be associated with computer work. These include musculoskeletal ailments of the upper extremities, back, shoulders, arms, hands and problems with the eyes. This paper reports on the findings of workplace assessments and interviews with professional translators with respect to the ergonomics of their workplaces and related health issues. A total of 36 professional translators working as freelancers, in institutional settings or in commercial enterprises were visited at their workplaces. Each workplace was assessed and compared to the recommendations about ergonomics available in the literature. In addition, interviews were held with translators immediately after the assessments about their current health status and any recent complaints. Many of the assessed workplaces evinced a high standard of ergonomically appropriate equipment and furniture. However, the equipment was in many cases not adjusted to suit the ergonomic needs of the individual using the workplace. Although the level of complaints was low overall, the highest number of health complaints related to the eyes, neck and shoulder girdle. Frequent breaks, changing position and doing short exercises to loosen up tense muscles would address these problems by helping to reduce tension and pain in the neck, shoulders and back and by providing rest for the eyes. Whenever possible, an ergonomic consultation is recommended. It is also recommended that ergonomic knowledge about proper workplace set-up should be provided in professional training.

La plupart des traducteurs professionnels occidentaux restent assis de longues heures devant leur écran et s'exposent ainsi aux problèmes de santé liés au travail à l'ordinateur. Parmi ces problèmes, il convient de citer les troubles musculo-squelettiques du dos, des épaules, des bras et des mains et la fatigue oculaire. Le présent article expose les résultats des évaluations et interviews réalisées auprès de traducteurs professionnels et axées sur l'ergonomie de leur poste de travail et les problèmes de santé associés. Les chercheurs se sont rendus aux postes de travail de 36 traducteurs professionnels installés à leur compte ou engagés dans des institutions ou des entreprises commerciales. Chaque poste de travail a fait l'objet d'une évaluation et d'une comparaison avec les recommandations en matière d'ergonomie fournies par la littérature. Des 
interviews ont, en outre, été menées avec les traducteurs à l'issue des évaluations dans le but de connaître leur état de santé et d'éventuels problèmes récents. Une grande partie des postes évalués présentent un équipement et un mobilier dotés d'un niveau élevé d'ergonomie. Toutefois, l'agencement n'est pas toujours adapté aux besoins ergonomiques de la personne assignée au poste de travail. Même si, dans l'ensemble, le nombre de problèmes de santé exprimés reste faible, la majorité d'entre eux concernent les yeux, la nuque et la ceinture scapulaire. Pauses fréquentes, changements de position et brefs exercices de relaxation permettraient de soulager ces problèmes en apaisant les tensions et les douleurs au niveau du dos, des épaules et de la nuque et en reposant les yeux. Il est recommandé de procéder à une analyse ergonomique dans la mesure du possible et de sensibiliser l'auditoire à l'agencement adéquat du poste de travail dans le cadre de formations professionnelles.

\section{INDEX}

Mots-clés: ergonomie, poste de travail, traduction professionnelle, évaluation de l'ergonomie, problèmes de santé

Keywords: ergonomics, workplace, professional translation, ergonomic assessment, health complaints

\section{AUTHORS}

\section{URSULA MEIDERT}

Institute of Occupational Therapy, School of Health Professions, Zurich University of Applied Sciences

\section{SILKE NEUMANN}

Institute of Occupational Therapy, School of Health Professions, Zurich University of Applied Sciences

\section{MAUREEN EHRENSBERGER-DOW}

Institute of Translation and Interpreting, School of Applied Linguistics, Zurich University of Applied Sciences

\section{HEIDRUN BECKER}

Institute of Occupational Therapy, School of Health Professions, Zurich University of Applied Sciences 